\title{
Comparison of consumer and nutritional behaviours of respondents aged 55 and older living in selected regions of Poland and France: BIO LIFE project - pilot studies
}

\author{
Magdalena Człapka-Matyasik', Małgorzata Fejfer', Anna Gramza-Michałowska', Jan Jeszka', \\ Olivier Fabre ${ }^{2}$, Francois Issler ${ }^{2}$ \\ ${ }^{1}$ Department of Human Nutrition and Hygiene, Poznan University of Life Sciences, Poznan, Poland \\ ${ }^{2}$ AGRIA Lorraine, Vandoeuvre-lès-nancy, France
}

\begin{abstract}
Człapka-Matyasik M, Fejfer M, Gramza-Michałowska A, Jeszka J, Fabre O, Issler F. Comparison of consumer and nutritional behaviours of respondents aged 55 and older living in selected regions of Poland and France: BIO LIFE project - pilot studies. J Pre-Clin Clin Res. 2014; 8(1): 3-8.
\end{abstract}

\begin{abstract}
The survey studied individuals aged 55 and older living in the Wielkopolska province of Poland and the Lorraine region in France to analyse and to compare consumer and nutritional behaviours. The results provided data on the nutritional behaviours and factors influencing the nutritional choices in these groups and found differences with its potential impact on consumer behaviour in both communities. The route to-and-from a shop, the weight of purchased products, and insufficient legibility of labels were found to be the most significant problems faced by the respondents in both countries. The quality and health aspects of food products were an important factor influencing the choice of food. A significant difference was noted between the approach of the Polish and the French respondents towards labelling food products with details concerning the recommended group of consumers; the French group was clearly reluctant to purchase food products with such labelling. In both studied groups, a frequent habit was observed of eating between meals. However, according to the responses by the tested individuals, fruits were most often chosen as snacks. The studies also revealed that the elderly preferred dishes with a strong and distinctive taste. These survey are a valuable source of information for local support centres for entrepreneurship, regional policy planning and local food producers. However, the scope of studies should be expanded to include groups from different regions and countries on a more representative group.
\end{abstract}

Key words

elderly, consumer behaviour, nutritional behaviour, shopping

\section{INTRODUCTION}

The distribution and dynamics of age in the European population indicates that aging societies are predominant. A demographic prognosis has revealed that Europe, as opposed to other countries, has the highest proportion of citizens aged 65 and older. In the last decade, the life expectancy of an average 65 -year old Pole increased by two years and three months. Poland is positioned slightly lower than France (76 years). where the average life expectancy reaches 80 years [World Population Prospects: The 2006 Revision]. Life expectancy in Poland is predicted to rise sharply in the near future. This tendency indicates the necessity to change the approach to developing services and products designed for this group of consumers. It may be assumed that a society with such an age structure is becoming a key challenge to many European countries. In response to this trend, numerous projects aimed at identifying the needs and expectations of aging societies are being undertaken. The needs related to food products and their distribution present a major challenge to the food industry and specialists

Address for correspondence: Magdalena Człapka-Matyasik, Department of Human Nutrition and Hygiene, Poznan University of Life Sciences, Poznan, Poland e-mail: magdalena.matyasik@up.poznan.pl

Received: 2 July 2013; accepted: 14 May 2014 in food and nutrition. The presented study follows this tendency and is a comparative analysis of Poland and France on the basis of the CREATOR programme of interregional cooperation. The aim of this project is to create new possibilities for industry in relation to the needs of people aged 55 and older. BIO LIFE (Business Innovation Opportunities - Life Improvement and Food for Elderly) is one of the sub-projects which focuses on the identification of expectations. habits and food preferences of this age group. Analysis of results will enable formulation of guidelines for the food industry in order to develop and expand the assortment of products addressed to the elderly, and will create possibilities for nutritionists to invent healthpromoting food for societies at risk of a higher prevalence of civilization diseases. The project comprises seven European countries: Finland, France, Hungary, Italy, Poland, Spain and Sweden, in which the studies on expectations, consumer behaviours and nutritional preferences were preceded by a description of the regions and an analysis of the market for +55 consumers. The presented study shows the initial results of survey studies carried out in two countries: Poland and France. The results will facilitate analysis and comparison of consumer development and distribution, as well as the profile of the food industry, particularly of small- and medium-size companies. 


\section{MATERIAL AND METHODS}

Consumer behaviour and nutritional preferences were assessed with using a questionnaire in English which was subsequently translated into Polish and French, and back into English. The questionnaire included 28 close-ended questions and the survey carried out simultaneously in the two countries between September - December 2011. The study was anonymous and focused on the target group of individuals aged 55 and older. All respondents were selected for the study by the snowball sampling method.

The examined population involved 107 individuals: 56 respondents from Poland (POL) living in the province of Wielkopolska and 51 respondents from the Lorraine region in France (FRA). The respondents comprised 77 women and 30 men (90 aged 55-75 and 17 aged +76). The evaluation of physical condition, nutrition parameters and blood biochemical parameters did not reveal any statistically significant differences between the Polish and French populations. The average BMI in both groups indicated obesity problems (FRA: $26.4 \mathrm{~kg} / \mathrm{m}^{2}$. POL: $26.9 \mathrm{~kg} / \mathrm{m}^{2}$ ). Analysis of distribution of the BMI value ranges did not show any statistically significant differences $(\mathrm{p}=0.62)$ in the number of respondents with optimal body weight $\left(\mathrm{BMI}<=24.9 \mathrm{~kg} / \mathrm{m}^{2}\right)$, overweight $\left(>=25.0 \mathrm{~kg} / \mathrm{m}^{2}\right)$ and obesity $\left(>=30 \mathrm{~kg} / \mathrm{m}^{2}\right)$. It should be noted that the French population more often showed the optimal body weight than the Polish respondents (FRA: 31.4\%. POL: $25 \%$ ) who were more frequently affected with obesity (POL: $11.8 \%$. FRA: $8.9 \%$ ).

About $30 \%$ of Polish and $63 \%$ of French respondents came from village and small town with less than 50,000 inhabitants. In both populations, app. $71 \%$ declared having a monthly income below the national average, and $22 \%$ in France and only $7 \%$ in Poland had a monthly income above the national average (Tab. 1). The income difference between Polish and French pensioners is also confirmed by the indicator defined as the ratio of the median individual gross pensions of 65-74 age category relative to median individual gross earnings of 50-59 age category, excluding other social benefits. Data obtained in 2009 indicated a value of $66 \%$ for pensioners in France (the highest among European countries) and 56\% for pensions Polish [EUROSTAT]. Among the French, 33\% of respondents declared being professionally

Table 1. Socio-economic characteristics of the study group

\begin{tabular}{|c|c|c|c|}
\hline \multirow{2}{*}{ Question } & \multirow{2}{*}{ Answers } & France & Poland \\
\hline & & \multicolumn{2}{|c|}{$\%$} \\
\hline \multirow{2}{*}{ Age } & $55-75$ & 96.1 & 73.2 \\
\hline & $>76$ & 3.9 & 26.8 \\
\hline \multirow{4}{*}{ Place of residence } & Village & 39.2 & 7.1 \\
\hline & Small town $<50,000$ inh. & 23.5 & 23.2 \\
\hline & City up to 500,000 inh. & 21.6 & 16.1 \\
\hline & City over 500,000 & 15.7 & 53.6 \\
\hline \multirow{4}{*}{ Education } & Basic (primary school) & 11.8 & 10.7 \\
\hline & Secondary school & 7.8 & 25 \\
\hline & Collage & 39.2 & 42.9 \\
\hline & Higher education/ university & 41.2 & 21.4 \\
\hline \multirow{3}{*}{ Earnings } & Below national average & 70.6 & 71.4 \\
\hline & Similar to national average & 7.5 & 21.4 \\
\hline & Above national average & 21.6 & 7.1 \\
\hline
\end{tabular}

active in comparison to $25 \%$ in the Polish population. $53 \%$ of the French and $23 \%$ of Polish respondents lived in a single household. Whereas $39 \%$ of study group from Wielkopolska and $43 \%$ from Lorraine lived in households shared with a partner. These populations differed significantly in the percentage of so-called 'multi-generation' households (shared with a partner and child/children; POL: 26.8\%; FRA: $2 \%)$. Statistical analyse was based on the Chi- square test $\left(\chi^{2}\right)$ performed in Statistica 10 to assess statistical significance of differences between groups $(\mathrm{p}<0.05)$.

\section{RESULTS}

Shopping and attitude towards food products. The data yielded by the questionnaire indicated that while purchasing food products the greatest obstacle for the French respondents was the distance from the shopping facilities (23.5\%) (Fig. 1). This may result from the fact that the majority of the examined group lived in the countryside or in small towns where shopping demanded using public transport or having a car. In Poland, the greatest problem for the respondents was the weight of purchased food products (37.5\%), whereas in the French population this reason was indicated only by $7.8 \%$. In both groups, the same percentage of respondents (19.6\%) reported having problems with the legibility of prices and labelling. Statistical analysis $\left(\chi^{2}=17.04 ; \mathrm{p}=0.009\right)$ confirmed a significant association between the access to food products, understood as the readability of packaging, problems with food transportation, and the country where such an inconvenience was encountered.

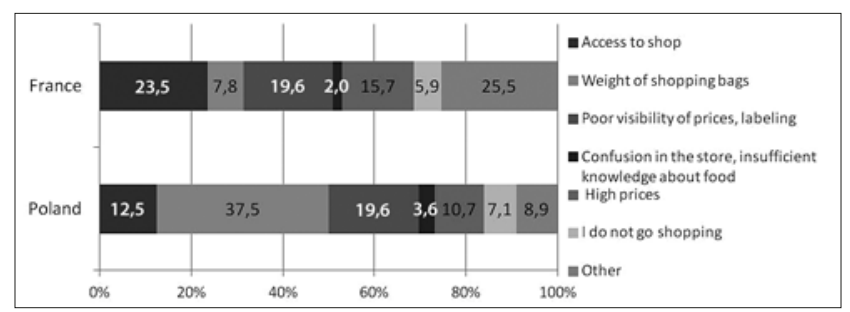

Figure 1. Problems reported during shopping in the French and Polish groups

The expectations of respondents relating to the size of food packages were comparable in both countries (Fig. 2). In both France and Poland, the great majority of respondents (POL: 76.8\%. FRA: $80.4 \%$ ) preferred purchasing products in smaller packages, despite the potentially higher costs. No statistically significant association was observed between the country and preferences for the size of food packaging $\left(\chi^{2}=1.62 ; \mathrm{p}=0.44\right)$.

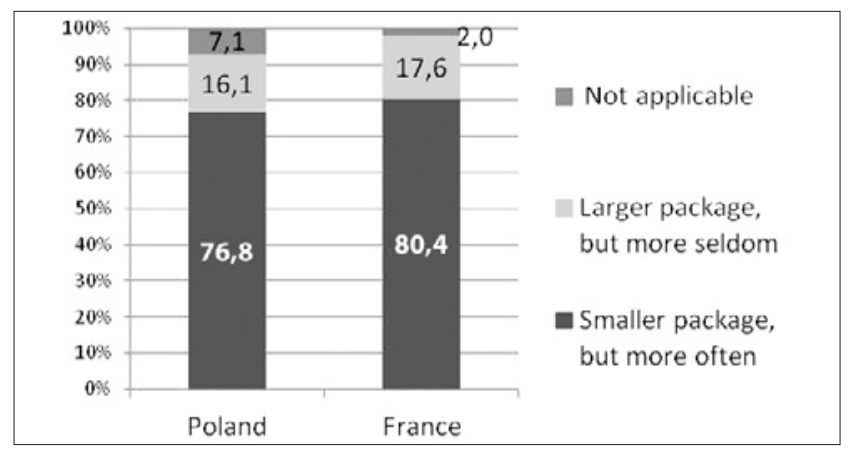

Figure 2. Preferences of food products in the French and Polish groups 
A statistically significant $\left(\chi^{2}=18.1 ; \mathrm{p}<0.001\right)$ relationship between place of residence and the habit of reading information on product labelling was noted. In this category, the differences were considerable. About $70 \%$ of the French respondents claimed that they always read the label of new products before buying, whereas in the Polish population, only $32 \%$ declared doing so and only $46 \%$ did it only occasionally.

The respondents were also asked to determine which information on the product labelling they found most important during shopping. No statistically significant association $\left(\chi^{2}=11.8 ; \mathrm{p}=0.11\right)$ related to the country was reported, and therefore the results were analysed as if they represented a homogenous group. In both countries, the respondents rated the composition of products $(35.8 \%)$ as most important, followed by the content of preservatives (14.2\%) and the calories of product (13.5\%). However, 57\% of the Poles and $46 \%$ of the French found the labels insufficiently legible and understandable Fig. 3.

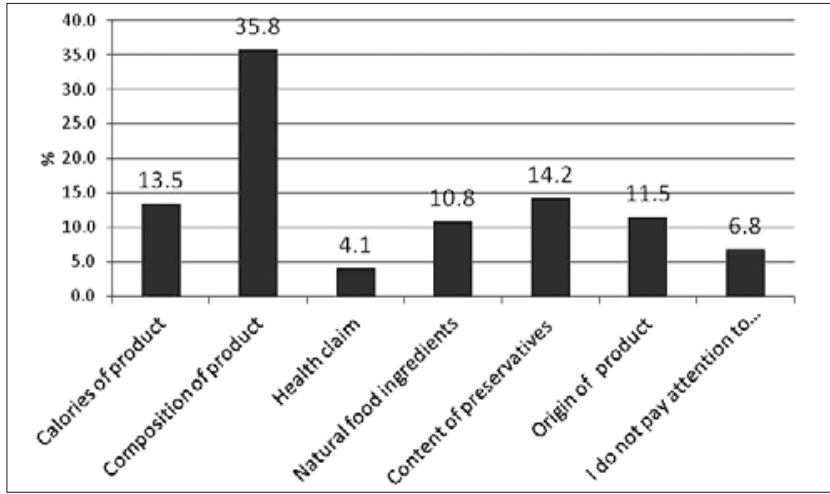

Figure 3. Significance of information on food product labels for consumers aged 55 and over

The questionnaire revealed an interesting profile of the priorities which consumers followed while choosing food products. With a closed-ended question, the respondents were asked to select the most appropriate answer out of 12 possible options. Both the French and the Poles most often chose quality and health-promoting characteristics as the most important parameters, followed thirdly by price.

A statistically significant association $\left(\chi^{2}=126.69 ; \mathrm{p}<0.0001\right)$ was observed between the country and the attitude towards the indication of the target group of consumers (e. g. 'for people aged $+55^{\prime}$ ) on the product labelling (Fig. 4.). Such information might facilitate purchasing the appropriate and recommended food products. In the French group, 51\% of respondents showed a negative attitude towards this claim, whereas in the Polish population none of the respondents gave such an answer. The results indicate that the population from Poland reacted positively to such claims on food products (definitely yes - $43 \%$; rather yes - 39\%).

It seems that the attitude of consumers towards new products on the market plays an important role in designing products intended for the elderly. The results did not indicate any statistically significant association between the country and the attitude towards novelties $\left(\chi^{2}=5.48\right.$; $\mathrm{p}=0.064)$. The majority of respondents in France and Poland (FRA: $45.1 \%$. POL: $44.6 \%$ ) declared an acceptance of new products, but their approach was rather cautious. Among the French population, more respondents (47.1\%) were open to new products than in the Polish group (32.1\%).

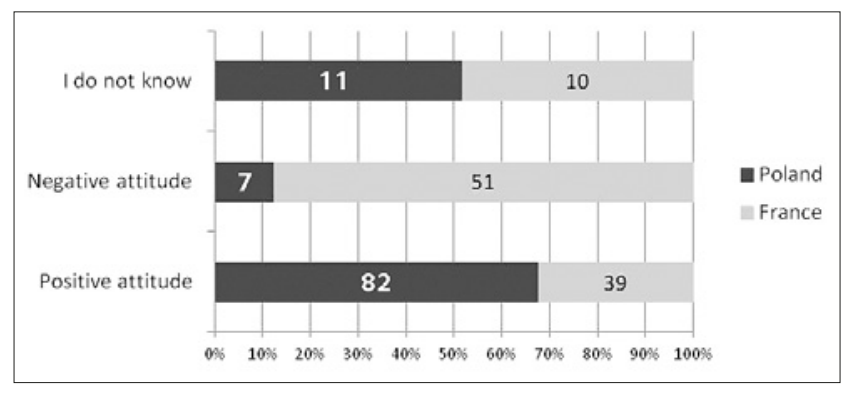

Figure 4. The attitude of the Polish and the French respondents towards the indication on the food products the target group of consumers $\left(X^{2}=126.69\right.$; $\mathrm{p}<0.0001)$

Despite the lack of statistical significance of the differences in the attitude towards novelties' in the Polish population a higher proportion of respondents were not interested in such products and purchasing such goods, in comparison with the French population $(7.8 \%)$.

The respondents were asked to describe their attitude towards food by responding to seven examples of statements. The results (Fig. 5) revealed that the Polish group found the dietary pattern very important (POL: $82.1 \%$. FRA: $19.6 \%$ ). In comparison with the Poles, the French respondents more often declared (FRA: 78.6\%; POL: 14.3\%) consuming food compatible with the preferences of their family and friends. The choices of French seniors were more frequently influenced by the recommendations given by a doctors (FRA: 78.6\%. POL: $16.7 \%)$. However, no statistically significant differences were found between the countries and the responses obtained to this question.

A significant association between the answers and the country of residence were observed for the question regarding following the recommendations of nutritionist $\left(\chi^{2}=35.6\right.$; p $>0.0001)$ : the French group followed such guidelines more often than the Poles (FRA: 78.4\%. POL: 39.2\%). The Polish seniors. even though they declared being motivated by the health-promoting qualities of food products, they were more often influenced than French respondents (FRA: 43.3\%; POL: $88.7 \%)$ by the price of foods $\left(\chi^{2}=16.76 ; p>0.0001\right)$ (Fig. 5$)$.

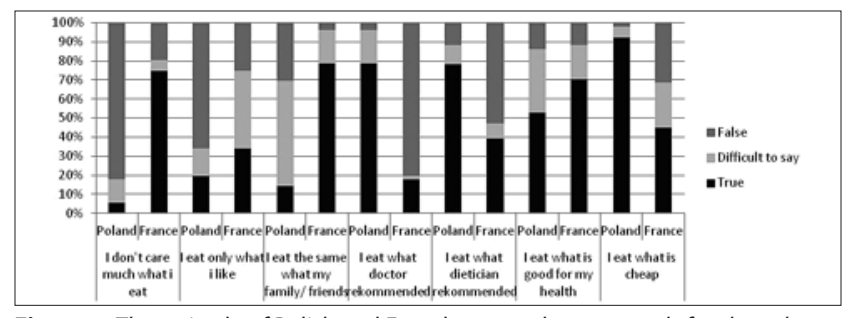

Figure 5. The attitude of Polish and French respondents towards food products

Nutritional habits and preferences. The results of the survey indicate that $67.3 \%$ of all respondents prepared their meals by themselves on a daily basis, and only $10.7 \%$ did so occasionally. In this case, no statistically significant differences related to the country of origin were observed $\left(\chi^{2}=2.36 ; p=0.67\right)$. An interesting discrepancy confirming the cultural differences was found in the question which concerned the frequency of eating out. In this case, the answers were clearly influenced by the place of residence $\left(\chi^{2}=15.1 ; \mathrm{p}<0.05\right)$. In the French group, the respondents declared eating out from several times per month (33.3\%) to several times per week (25.5\%), whereas in the Polish population only $4 \%$ of respondents admitted to having such a nutritional habit. 
The groups were asked to enumerate the most frequent problems encountered while preparing meals. The majority of seniors (POL: 66.1\%; FRA: 52.9\%) declared not having any difficulties with such an activity. However, the respondents who prepared their meals by themselves indicated that they had problems with using excessively large food portions (POL: 10.7\%; FRA: 2\%) and with opening the packages (FRA: 7.8\%; POL: $8.9 \%)$.

The respondents were also asked about the habit of eating between meals. In the case of this question, as well as the one concerning the most common snacks, there was no statistically significant association between the results and the country of origin; therefore, the results were evaluated as if all respondents formed a homogenous group. Only one out of four denied having the habit of eating between meals. Regularity of snacks consumed between the main meals was declared by $33.6 \%$ of respondents, and $42.1 \%$ declared doing it from time to time.

However. the respondents answered that between meals they most often consumed fruit (41\%), followed by sweets (chocolate bars, candies, salty snacks such as potato crisps) and dairy products (12.4\%).

The respondents declared preferring dishes with a distinct and strong taste. The French seniors most often chose sweet dishes (FRA: 25.5\%) while the Polish group selected salty products (POL: $33.9 \%$ ).

Additionally, the respondents were asked about the source of knowledge of healthy nutrition. In this case, a statistically significant association was observed between the answers and the place of residence $\left(\chi^{2}=34.69 ; \mathrm{p}<0.0001\right)$. The Poles were most often influenced by television (POL: 23.2\%; FRA: $14.3 \%)$, whereas the French group was influenced by the Internet (POL: $8.7 \%$; FRA: 31\%). The Polish seniors also followed the guidelines from illustrated magazines and the recommendations of family members, while the French group chose television, daily journals and books as the source of information (Fig. 6).

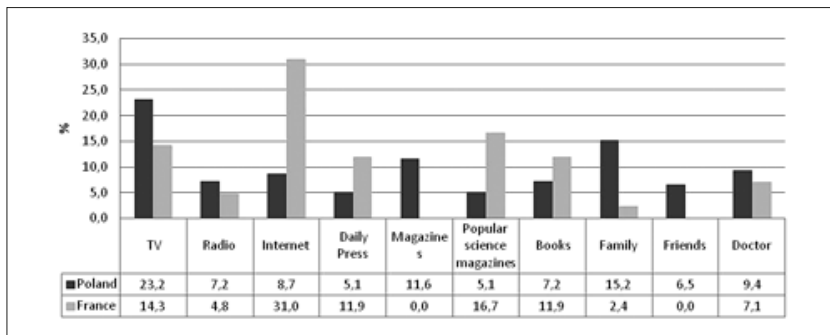

Figure 6. The source of nutritional knowledge of the Polish and the French study groups

\section{DISCUSSION}

The seniors, as consumers, felt strongly attached to tradition and frequently to one shop, place or brand. The average senior showed a rather reserved model of consumption and may be described as punctual, reliable, and usually loyal but meticulous in calculating expenses [Becker, 1997]. All these traits, together with reduced physical and mental capability and progressively deteriorating health and perception, make +55 consumers a group with special needs and expectations, bearing in mind the predicted growth in the size of this age group in the forthcoming years.
The attempt to define and compare the most frequent problems faced by the elderly while purchasing food products indicated that the food market should be adapted to their needs and expectations. The respondents, particularly the French, declared having problems with accessing shopping facilities. This problem existed in rural communities and resulted from a lack of a car or public transport. The example of large urban centres shows that in forthcoming years it will be necessary to organize means of transportation and the ways of delivering food products to smaller communities of seniors where, in the opinion of the authors, the needs will be increasing [AENEAS project - Attaining Energy-Efficient Mobility in an Ageing Society].

Apart from the results of the presented study, some other surveys have confirmed that one out of four respondents aged 60 and older is not able to go shopping alone, and has to rely on somebody's help [Świtała, 2009 and Meneely, 2009]. The literature shows that approx. $35 \%$ of people over 60 years of age have difficulties with accessing grocery shops. The problems defined in the literature also include the size of shopping facilities. height of shelves. frequent changes in product arrangement and the distance between the shop and parking area [Oates et al., 1996]. The positive factors highlighted by the seniors are the friendly and supportive personnel and the possibility for using additional services (e.g. a post office). Furthermore, the literature suggests combining shopping with other social or recreational activities addressed to the elderly (Miller \& Kim, 1999; Rosela, 2001).

The presented survey highlights a problem related to the weight of purchased products. It shows that this group of consumers preferred products in smaller packaging units, even if it was associated with a higher frequency of shopping or with higher prices. This information seems to be a useful tip for producers who often offer bigger packages at a lower price. Leighton \& Seaman (1997) reported a similar observation of the population of elderly people in Scotland. These authors found that for $31 \%$ of respondents the size of packaging and the volume of product available in shops was too large for single households. $82 \%$ of the elderly confirmed that they could more efficiently utilize food in smaller packaging units. It seems that the best solution is to leave the choice of product size to the consumer.

Based on the presented survey, it was shown that consumers aged 55+ paid considerable attention to information on the labelling, and their choice of food was influenced by the quality and health-promoting aspects of food products. This was also confirmed in the studies by Meneely [2009] who found that $59 \%$ of senior consumers read the labels of food products. The elderly pay special attention to the composition and natural qualities, i.e. lack of preservatives. It seems that this situation results from the fact that the elderly are attached to traditional tastes and pay special attention to their health. In order to make an informed choice, the $55+$ consumer should be able to clearly read and understand the label. The development of such packages should be included on the list of priorities for specialists in food labelling and packaging. The studies by Meneely [2009] confirmed that elderly citizens highlight problems with the legibility of labels, which obliged them to rely on somebody's help and made them feel uncomfortable. This thesis was also confirmed by Oates et al. [2009] who showed that the elderly preferred products in light-coloured packaging with light labelling since it was easily readable for them. These authors 
suggested that the labelling of products addressed to seniors should be written with an appropriate font to help them read nutritional information [Mennely, 2009].

In the presented study, two different attitudes were reported by the Polish and French seniors towards the possibility of placing target group information on the product (e.g. 'product recommended for people over 60 years of age'). The Polish seniors declared that this information would be useful for them, as opposed to the French who showed an expressively negative attitude. This discrepancy may result from a different approach to the senior stage of life and cultural differences. Some respondents do not want to be perceived as elderly and are not interested in purchasing food products dedicated to this age group and labelled, for example, with an age range $(+55)$. The placement of such claims on products is a challenging initiative that requires thorough consideration, particularly in western Europe where the tradition and perception of the elderly is different from that, for instance, in Poland.

The differences between the French and Polish seniors were also associated with the recommendations by qualified nutritionists and the price in the process of choosing food products. The French seniors living in the Lorraine region more often followed a nutritionist's guidelines (this profession is more commonly accepted), while in Poland the elderly consumers mostly considered the price of products. European studies evaluating the attitude of consumers towards food, nutrition and health carried out in all EU member states in 1997, showed that the most important factor considered in the process of purchasing food was the quality/freshness of products (74\%) and the price (43\%) was second [Kafatos et al., 1997]. The seniors interviewed in the above-mentioned survey presented a point of view common for all EU citizens. A study performed in the same year on the source of knowledge of healthy nutrition, indicated that television was the main opinion-making body. For 26\% of respondents, health care workers were a reliable source of information. It should be noted that this study did not include a separate category for nutritionists [Becker et al., 1997]. Another study carried out on the elderly population in Taiwan confirmed that nutritionists were an important source of information only for $8 \%$ of the seniors, which was much lower than health care workers (48.3\%) and nurses (29.2\%) [Wei Lin \& Ya-Wen Lee, 2005].

The data from the presented study shows that $67.7 \%$ of respondents aged 55 and older prepared their meals by themselves on a daily basis. The same observations were reported by Kozłowska et al. [2006]. The habit of eating out is not popular in Poland. It is much more common among the French; about one-fourth of the respondents in Lorraine eat out several times per week. It should be noted that in Europe the model of nutrition is slightly different than in USA where, according to the literature, $40 \%$ of people aged 60 and older eat out at least once a month [Lahue, 2000].

The habit of eating between meals was common among the respondents. However, it should be emphasized that seniors most often selected fruit. A similar behavioural pattern was also observed by other authors [Gabrowska \& Spodarek, 2002; Cross AT et al., 1995]. Since eating between meal leads to overconsumption of food, overweight and obesity, avoidance is recommended in order to control body weight [Marmonier et al., 2002]. In the literature, there are several reports confirming that the consumption of more, although limited, meals each day may facilitate controlling body weight [Kirk \& Cursiter, 1999], decrease total cholesterol concentration and LDL [Jenkins. 1989], and help control glucose concentration [Jenkins. 1997]. Corresponding results were reported in SENECA (Survey Europe on Nutrition in the Elderly) studies which evaluated the nutritional habits of the elderly citizens in 12 European countries, and revealed that individuals who ate more frequently showed a better level of nutrition than those who ate only the main meals [de Groot \& van Staveren, 2002].

The habit of eating between meals observed in the presented survey may also be a consequence of poor appetite among the elderly and their unwillingness to eat large meals. which are replaced with snacks. Furthermore. it should be emphasized that the taste preferences of the elderly may be different from the young (confirmed in papers already published) [Graaf et al., 1994]. These differences are conditioned by changes in the taste buds which are manifested as a decrease in the perception threshold. They may also result from other ailments or medicines, and be associated with a weaker perception of food taste and smell [Jabłoński \& Kaźmierczak, 2005; Grzymisławski \& Gawęcki, 2010]. These dysfunctions hinder the pleasure of eating and the composition of a varied and rational diet. The studies confirmed that the elderly prefer spicy dishes with a distinctive taste.

\section{CONCLUSIONS}

1. The quality and health aspects of food products were an important factor influencing the choice of food by the elderly, regardless of the place of residence.

2. The biggest problem encountered by the elderly during shopping was the route to-and-from the shopping facilities (particularly for individuals living in rural areas), and the weight of purchased goods.

3. All the respondents, regardless of place of lresidence, preferred small packages of food facilitating transport and utilization.

4. Regardless of the place of residence, seniors paid special attention to the composition and health-promoting aspects of food products.

5. A significant difference was observed in the approach of the French and the Polish respondents to the labelling of food products with information directed at the target consumer group. The French population showed an expressively negative attitude towards such information placed on the packaging of food products.

6. Both Polish and French seniors declared an acceptance of novelties on the market, but they approached them with caution. In the Polish population, more individuals were not interested in such products and denied utilizing them.

7. The majority of respondents declared a preference for products with a distinct, spicy taste. The French preferred sweeter tastes, while the Poles selected saltier tastes.

8. During shopping, the French seniors more often followed the recommendation of nutritionists, as opposed to the elderly Polish citizens.

9. The Polish seniors were more often motivated by the price while selecting food products during daily shopping. 


\section{SUMMARY}

It is emphasized that the comparison of consumer and nutritional behaviours between the elderly from the Lorraine region of France and the province of Wielkopolska in Poland was a pilot study on unrepresentative groups. Nevertheless, the obtained data did not reveal many significant differences between the study groups from either countries. The biggest discrepancies observed were associated rather with cultural differences that should be considered in developing food products addressed to seniors living in the selected geographical regions. Differences were observed in the negative attitude of the French seniors towards placing information on the target age group of consumers on food labelling. Moreover, the French population more often followed the recommendations of nutritionists in the process of choosing food products. The respondents from both countries used different sources of information on the rules of optimal nutrition, which should be taken into consideration when planning the nutritional education for this group of people.

These survey studies are a valuable source of information for local support centres for entrepreneurship. regional policy planning and local food producers. However. the scope of studies should be expanded to include groups from different regions and countries and should be compared with the preferences of other EU citizens. Undoubtedly. they may serve as a source of knowledge of the food industry that could help to adapt products and services to the needs and expectations of a society with a changing demographic structure.

\section{REFERENCES}

1.AENEAS - Good Practice Fact Sheets - European project in the framework of the Intelligent Energy Europe (IEE). www.aeneas-project. eu (access: 02.07.2013).

2. Becker W, Schmitt A. Kearney M, Lennernas M, Fjellstrom C, Giachetti I. Remaut de Winter AM. Influences on food choice perceived to be important by nationally-representative samples of adults in the European Union. Eur. J. Clin. Nutr. 1997; 51 (Suppl 2): 8-15.

3. Cross AT, Babicz D. Cushman LF. Snacking habits of senior Americans. J. Nutr. Elder. 1995; 14 (2-3): 27-38.
4. Gabrowska E, Spodaryk M. Assessment of dietary intake of elderly people living in Krakow. Żyw Człow Metab 2002; 29 (Suppl): 203-208.

5. Graaf C, Polet P, Staveen A. Sensory Perception and Pleasantness of Food Flavors in Elderly Subjects. J. Gerontol. 1994; 49 (3): 93-99.

6. Groot CP, Staveren WA. Under-nutrition in the European SENECA studies. Survey in Europe on Nutrition and the Elderly. a Concerted Action. Clin Geriatr Med. 2002; 18(4): 699-708.

7. Grzymisławski M, Gawęcki J. Żywienie Człowieka zdrowego i chorego. PWN. Warsaw. 2010 p. 81-82 (in Polish).

8.EUROSTAT: www.epp.eurostat.ec.europa.eu (access: 02.07.2013).

9. Jabłoński E, Kaźmierczak U. Nutrition of the elderly. Gerontol. Pol. 2005; 13: 48-54.

10. Jenkins DJ. Carbohydrate tolerance and food frequency. Brit. J. Nutr. 7. 1997; Suppl 1: 71-81.

11. Jenkins DJA, Wolever TMS, Vuksan V, Brighhen F, Cunnane SC. Nibbling versus gorging: metabolic advantages of an increased meal frequency. New Eng. J. Med. 1989; 321:929-34.

12. Kafatos A, Kearney JM, Giachetti I, Remaut de Winter. de Graca P. Lappalainen R. Sources used and trusted by nationally-representative adults in the European Union for information on healthy eating. Eur. J. Clin. Nutr. 1997; 51 (Suppl 2): 16-22.

13. Kirk TR, Cursiter MC. Long-term snacking intervention did not lead to weight gain in free-living man. Scand. J. Nutr. 1999; 2 (Suppl 34): 3-17.

14. Kozłowska K, Szczecińska A, Roszkowski W, Brzozowska A, Saba A. Perception of convenience food by older people living in Warsaw (based on the example of vegetable soups). Pol. J. Food Nutr. Sci. 2006; 15/56 (2): 227-233.

15. Lahue P. The new mature market. Restaurant Hospitality. 2000; 84 (1): $51-56$

16. Leighton C, Seaman C. The elderly food consumer: disadvantaged? J. Consum. Stud Home Econ. 1997; 21 (4) 363-370.

17. Marmonier C, Chapelot D, Fantino M. Snacks consumed in a non-hungry state have poor satiating efficiency: influence of snack composition on substrate utilization and hunger. J. Am of Clin. Nutr. 2002; 76 (3): 518-28.

18. Meneely L. Elderly consumers and their food store experiences. J. Retail. Cons. Services. 2009; 16 (6): 458-465.

19. Miller N, Kim S. Importance of older consumers to small business survival: evidence from Iowa. J. Small Bus Manage. 1999; 37: 1-15.

20. Oates B, Shufeldt L, Vaught B. A psychographic study of the elderly and retail store attributes. J. Cons. Marketing. 1996; 13 (6): 14-27.

21. Rosel N. Inconspicuous consumption: How a small sample of rural elders see images in the media. Generations. 2001; 35 (3): 47-51.

22. Świtała M. The self-assessment of health condition and its effect upon the behavior of senior consumers. Gerontol. Pol. 2009; 17 (3): 129-136.

23. Wei Lin. Ya-Wen Lee. Nutrition knowledge. attitudes. and dietary restriction behavior of the Taiwanese elderly. Asia Pac. J. Clin. Nutr. 2005; 14 (3): 221-229.

24. World Population Prospects: The 2006 revision. United Nations 